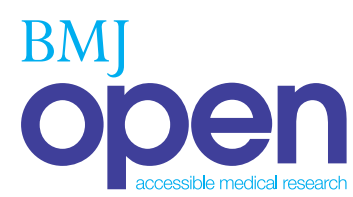

\title{
The impact of preprinted prescription forms on medication prescribing errors in an ophthalmology clinic in northeast Thailand: a non-randomised interventional study
}

\author{
Thuss Sanguansak, ${ }^{1}$ Michael G Morley, ${ }^{2}$ Yosanan Yospaiboon, ${ }^{1}$ Alice Lorch, ${ }^{3}$ \\ Bethany Hedt, ${ }^{4}$ Katharine Morley ${ }^{5}$
}

To cite: Sanguansak T, Morley MG, Yospaiboon Y, et al. The impact of preprinted prescription forms on medication prescribing errors in an ophthalmology clinic in northeast Thailand: a non-randomised interventional study. BMJ Open 2012;2:e000539. doi:10.1136/

bmjopen-2011-000539

- Prepublication history for this paper is available online. To view these files please visit the journal online (http:// dx.doi.org/10.1136/ bmjopen-2011-000539).

Received 28 October 2011 Accepted 23 January 2012

This final article is available for use under the terms of the Creative Commons Attribution Non-Commercial 2.0 Licence; see http://bmjopen.bmj.com

For numbered affiliations see end of article.

Correspondence to Dr Katharine Morley; kemorley@partners.org

\section{ABSTRACT}

Objectives: To understand the incidence and types of medication prescribing errors in a low resource setting ophthalmology clinic and to determine the impact of a preprinted prescription based on the hospital formulary (FormularyScript) on medication prescribing errors.

Design: Non-randomised interventional study.

Setting: Ophthalmology clinic in a teaching hospital in northeast Thailand.

Participants: 4349 handwritten prescriptions collected from October 2009 to December 2009, and 4146 FormularyScripts collected from February 2010 to May 2010.

Primary and secondary outcome measures: All prescriptions from the handwritten and

FormularyScript groups were analysed for medication error rates by types (legibility, ambiguous, incomplete, abbreviation and accuracy) and subtypes (drug name, strength, which eye, route and dispensed amount).

Results: Comparison of error rates in the two groups showed a 10 -fold reduction in the overall error rate using FormularyScript $(32.9 \%-3.5 \%, p<0.001)$. FormularyScripts were associated with statistically significant $(p<0.001)$ decreases in the following error types: legibility $(16.1 \%-0.1 \%)$, incomplete $(16.1 \%-0.1 \%)$ and abbreviation $(3.1 \%-0.3 \%)$. There was no statistically significant change in accuracy errors $(0.8 \%-0.6 \%, p=0.21)$. Ambiguous errors increased with FormularyScripts $(0.6 \%-2.5 \%$, $p<0.001$ ), likely due to the introduction of new ways to make errors. Decreases were seen in all legibility, abbreviation and accuracy error subtypes, and four out of six incomplete error subtypes. There were statistically significant increases in both ambiguous error subtypes: which eye $(0.3 \%-2.5 \%, p<0.001)$ and drug name $(0.3 \%-0.6 \%, p=0.03)$.

Conclusions: In our study population, outpatient medication prescribing errors were common and primarily due to legibility and incomplete error types. A preprinted prescription form has the potential to decrease medication prescribing errors related to legibility, incomplete prescribing information and use

\section{ARTICLE SUMMARY}

Article focus

- Little is known about the frequency and types of medication prescribing errors in developing countries, especially outpatient settings.

- Computerised prescribing systems are usually not feasible in low resource settings; however, a preprinted form may be an alternative.

Key messages

- Medication prescribing errors are common in outpatient ophthalmology clinics and are primarily due to legibility and incomplete information.

- Preprinted prescription forms have the potential to decrease medication prescribing errors related to legibility, incomplete prescribing information and use of unacceptable abbreviations without changing the overall rate of accuracy errors, but new error types can be introduced.

- Any new medication prescribing system needs to be carefully monitored for unintended consequences. Working closely with physicians and pharmacists to optimise design and providing adequate training for users are important considerations in minimising the introduction of new ways of making errors.

Strengths and limitations of this study

- The main strengths of this study are that it demonstrates that a low cost alternative to computerised prescribing exists and is effective at reducing the most common types of medication prescribing errors.

- Important limitations of this study are that it is a non-randomised study conducted at a single site, the subjective nature of determining and classifying error types such as legibility, the FormularyScript did not include all necessary medications and physicians were aware that the prescriptions were being analysed for prescribing errors. 
of unacceptable abbreviations without changing the overall rate of accuracy errors. However, new error types can occur.

\section{INTRODUCTION}

Accurate medication prescribing is an important process in ensuring the best possible outcomes in the treatment of diseases. Research from developed countries suggests that most prescription errors result from illegibility and incomplete prescribing information. One study in the USA found a prescription medication error rate of $7.6 \%$ in the outpatient setting, with errors in frequency and dose being the most common type. ${ }^{1}$ A study from an ophthalmic specialty hospital in England found $45 \%$ of all medication errors occurred in the outpatient department, with errors in prescription writing being the most common. $^{2}$ A preprinted order sheet was shown to reduce medication errors twofold in a randomised controlled trial in a paediatric emergency department in the USA. ${ }^{3}$

Little is known about the incidence and types of medication prescribing errors in developing countries. A review of the literature shows a handful of descriptive studies looking at prescribing errors in outpatient settings. Studies from Bahrain, ${ }^{4}$ Nepal, ${ }^{5}$ India, ${ }^{6}{ }^{7}$ Saudi Arabia $^{8}$ and Nigeria ${ }^{9}$ found a high incidence of errors in prescription writing, including illegibility and incomplete prescribing information. Other issues cited were failure to use generic medication names, non-adherence to national formulary and inadequate medication labelling. Solutions such as computerised physician ordering systems and electronic prescription writing programs are often used to address these issues. Research in the USA has suggested that advanced computerised physician order entry systems using decision support software have the greatest impact in preventing medication errors and adverse drug reactions. ${ }^{1}$ However, computerised prescribing systems are usually not feasible in developing countries due to resource constraints.

The goals of this study were to determine the incidence and types of medication prescribing errors in an outpatient ophthalmology clinic in a low resource setting and to evaluate whether or not a preprinted prescription with prompts for prescribing information is an effective, low cost alternative for reducing medication prescribing errors.

\section{METHODS}

This is a non-randomised interventional study comparing medication prescribing errors before and after the intervention of a preprinted prescription form based on the hospital formulary (FormularyScript). The FormularyScript includes names and prescribing information for selected medications. It includes prompts for all prescribing information, such as dose, frequency and route (figure 1 ).

\section{Study site and population}

The study was conducted in the outpatient ophthalmology clinic of Srinagarind Hospital, Khon Kaen
University in northeast Thailand. A total of 28 ophthalmology residents, fellows and faculty participated in the study. All prescriptions written in the outpatient ophthalmology clinic during the study period were included, unless the patient did not consent or the physician was excluded from participation in the study. Physicians were excluded if they participated in the design and implementation of the research study. Four faculty ophthalmologists elected not to participate (table 1).

\section{Data collection}

During the first phase of the study, baseline data were collected on the frequency and types of medication prescribing errors on the handwritten prescription traditionally used in the clinic.

The target sample size of prescriptions was 3000 to achieve $80 \%$ power to detect a $30 \%$ reduction in rate of errors and assuming an error rate of $5 \%$ under the current system $(\alpha=0.05)$. Medications were recorded on the data collection spreadsheet using the name written on the prescription. Prescriptions that were written but never filled were included in the study. Prescriptions were omitted if they were handwritten on a FormularyScript (table 1).

After completion of the first phase, the FormularyScript was introduced to the physicians in the ophthalmology clinic with instructions in its use. Over the next month, they were given feedback if it was not completed correctly, and design modifications were made based on the results. The second phase of the study collected data on the frequency and types of medication prescribing errors on the FormularyScript and used the same target number of prescriptions.

\section{Prescription review process}

Data for each prescription were entered into the study database along with a digital photo of the prescription and the prescribing information from the patient's chart. A three-step review process was used on all prescriptions. The first review was done by a pharmacist, who recorded any medication prescribing errors on the prescription when it was brought to the hospital pharmacy. Agreement between medication information on the prescription and in the chart was done by a research assistant trained as a pharmacy technician at the time of entry into the study database. The second reviewer, a pharmacy technician, reviewed all prescriptions and prescribing information from the patient chart using the digital photos. Discrepancies between the first and second reviews were flagged. All prescriptions were reviewed a third time by one of the investigators (KM), to make sure that there was agreement in classifying errors. If necessary, a fourth investigator was consulted to resolve disagreements.

\section{Error types and definitions}

Medication prescribing errors are any type of deviation from a complete, accurate and legible prescription. They 
Figure 1 Reproduction of the FormularyScript. Patient demographic and accounting information is in Thai. Final version used in study had prescribing information in Thai. Three medications can be written on one form. A number is written next to each medication and corresponds with the prescribing information. Medications not listed can be written in blank spaces.

โรงพยาบาลศรีนครินทร์ คณะแพทยศาสตร์ มหาวิทยาลัยขอนแก่น

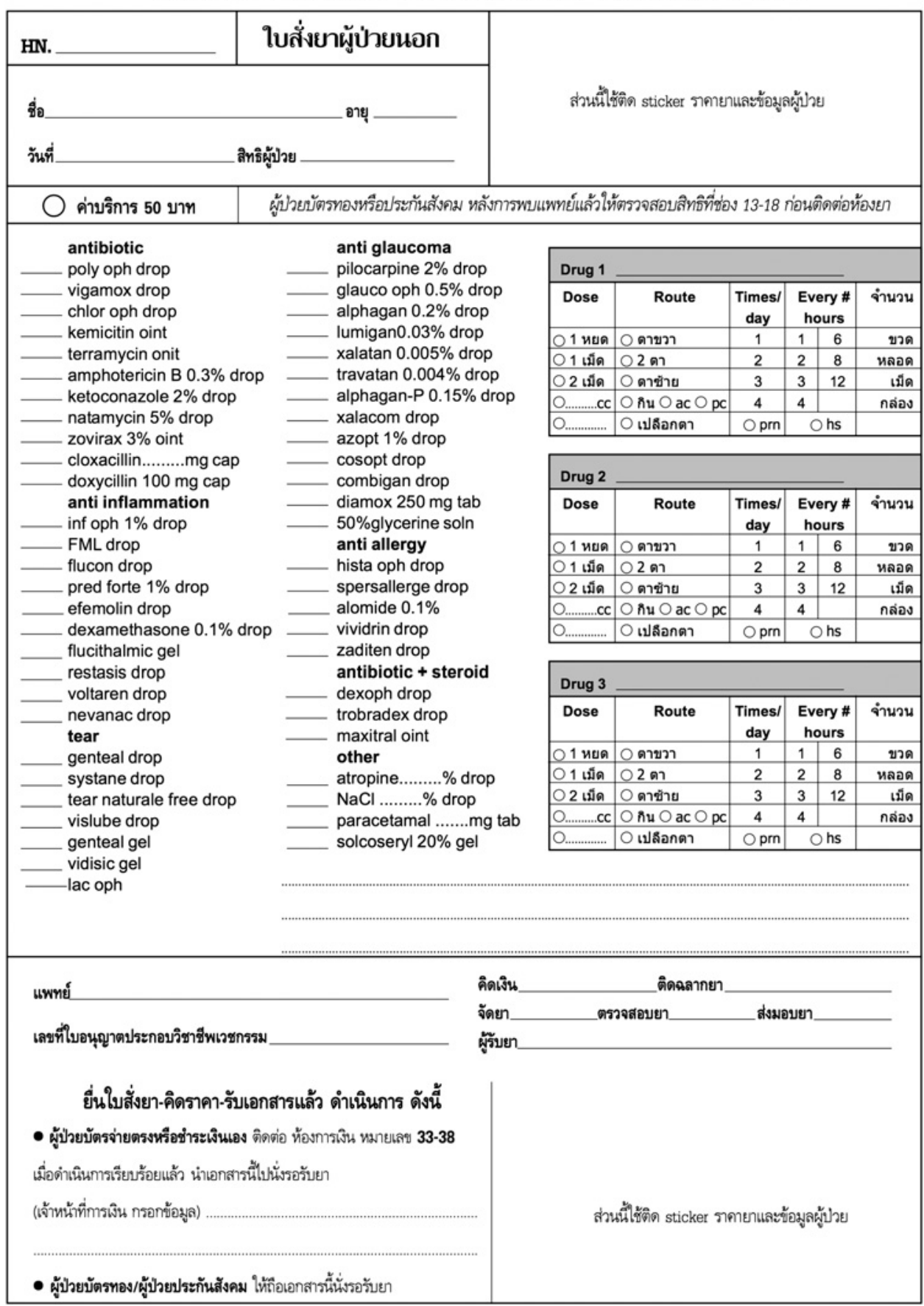

OPD 801-ยnh้ update 26-01-53

refer only to errors on the prescription, not the prescribing decision or dispensed medication. The error types and definitions used in this study were based on the prescription error classifications used at Srinagarind Hospital. They are as follows: (1) legibility: element of prescription difficult to decipher by pharmacist because writing on prescription was not clear; (2) ambiguous: element of prescription that was clearly written but could be misinterpreted by pharmacist (eg, use of $\AA$ for proprietary drugs could be misinterpreted as right eye); (3) incomplete: omission of required prescription element as determined by the medication; (4) abbrevi- ation: use of unacceptable abbreviation, as determined by pharmacy, for medication name on prescription and (5) accuracy: element of prescription with different information than was written in chart or based on dosing requirements for that medication. Discrepancies between generic and trade names were not considered errors. The error subtypes, based on the required prescription elements for a given medication, were medication name, strength, route, which eye, frequency and dispense amount. Some medications only have one form or strength, in which case these elements would not be required. The same error types were used in both 


\begin{tabular}{lll}
\hline \multicolumn{3}{c}{ Table 1 Description of study population } \\
\hline & Handwritten & $\begin{array}{l}\text { Formulary- } \\
\text { Script }\end{array}$ \\
\hline $\begin{array}{l}\text { Number of prescriptions } \\
\text { Total collected }\end{array}$ & 4349 & 4893 \\
Not filled at pharmacy & $935(21.5 \%)$ & $246(5.0 \%)$ \\
Handwritten medication & $\mathrm{NA}$ & 747 \\
$\begin{array}{l}\text { on FormularyScript } \\
\text { Total in study population }\end{array}$ & 4349 & 4146 \\
\% Prescriptions written by physician training level \\
$\begin{array}{l}\text { First-year resident } \\
\text { physicians }\end{array}$ & 23.2 & 26.6 \\
$\begin{array}{l}\text { Second-year resident } \\
\text { physicians }\end{array}$ & 28.9 & 29.2 \\
$\begin{array}{l}\text { Third-year resident } \\
\text { physicians }\end{array}$ & 28.9 & 31.7 \\
$\begin{array}{l}\text { Fellows (subspecialty } \\
\text { training after residency) }\end{array}$ & 6.3 & 2.5 \\
\begin{tabular}{l} 
Faculty physicians \\
\hline
\end{tabular} & 12.7 & 10.0 \\
\hline
\end{tabular}

handwritten and FormularyScript. However, what was considered a legibility or ambiguous error differed in the two groups. For example, a legibility error on Formulary Script occurred if the circle marked overlapped two medication names, and an ambiguous error on Formulary Script occurred if there was a question about the number next to drug name correlating with the prescribing information.
Data analysis

The frequency of the error types and error subtypes across all prescription elements between handwritten and Formulary Scripts was compared using a two-sample test of proportions. A two-sample test of proportions was also used to compare the frequency of error types on each element of the prescription. Statistical analysis was performed using Stata V.9 statistical software (StataCorp. 2005, Stata Statistical Software: Release 9; StataCorp LP.). Because the required elements for a prescription varied by medication, a table of the possible error types for each medication was generated. If an error type was not possible, it was not included in the denominator when the error rates were calculated.

\section{RESULTS}

\section{Error types}

A total of 4349 handwritten prescriptions and 4146 FormularyScripts were included in the data analysis. The overall rate of any medication prescribing error on a prescription using handwritten prescriptions was $32.9 \%$ compared with $3.5 \%$ using FormularyScripts $(p<0.001)$. The rates of the five error types on a prescription were calculated and compared for handwritten and FormularyScripts (table 2). Statistically significant decreases $(\mathrm{p}<0.001)$ using FormularyScripts were seen in the following error types: legibility $(16.1 \%-$ $0.1 \%)$, incomplete $(16.1 \%-0.1 \%)$ and abbreviation

Table 2 Rates by error type and subtype in handwritten versus FormularyScript

\begin{tabular}{lccrrl}
\hline Error type and subtype & Handwritten, $\mathbf{N}(\%)$ & FormularyScript, $\mathbf{N}(\%)$ & $\boldsymbol{\Delta} \%$ & $\mathbf{p}$ Value & $\mathbf{C l}$ \\
\hline Legibility & $4349(16.1)$ & $4146(0.1)$ & 16.0 & $<0.001$ & 14.9 to 17.1 \\
Drug name & $4349(5.7)$ & $4146(0.1)$ & 5.6 & $<0.001$ & 4.9 to 6.3 \\
Strength & $1183(5.8)$ & $904(0.0)$ & 5.8 & $<0.001$ & 4.5 to 7.2 \\
Route & $564(2.3)$ & $161(0.0)$ & 2.3 & 0.052 & 1.1 to 3.5 \\
Which eye & $3785(6.5)$ & $3985(0.0)$ & 6.5 & $<0.001$ & 5.7 to 7.3 \\
Frequency & $4336(4.6)$ & $4144(0.0)$ & 4.6 & $<0.001$ & 4.0 to 5.2 \\
Dispense amount & $4336(1.3)$ & $4144(0.0)$ & 1.3 & $<0.001$ & 0.9 to 1.6 \\
Ambiguous & $4349(0.6)$ & $4146(2.5)$ & -1.9 & $<0.001$ & -2.4 to -1.3 \\
Drug name & $4336(0.3)$ & $4144(0.6)$ & -0.3 & 0.03 & -0.6 to -0.0 \\
Which eye & $3785(0.3)$ & $3985(2.5)$ & -2.2 & $<0.001$ & -2.6 to -1.6 \\
Incomplete & $4349(16.1)$ & $4146(0.1)$ & 16.1 & $<0.001$ & 14.8 to 17.0 \\
Medication name & $4344(12.3)$ & $4145(0.0)$ & 12.3 & $<0.001$ & 11.3 to 13.2 \\
Strength & $1184(6.0)$ & $904(0.0)$ & 6.0 & $<0.001$ & 4.6 to 7.3 \\
Route & $563(15.3)$ & $161(1.2)$ & 14.1 & $<0.001$ & 10.6 to 17.5 \\
Which eye & $3785(0.2)$ & $3986(0.1)$ & 0.0 & 0.70 & -0.1 to 0.2 \\
Frequency & $4346(0.5)$ & $4146(0.0)$ & 0.5 & $<0.001$ & 0.3 to 0.7 \\
Dispense amount & $4346(0.1)$ & $4146(0.0)$ & 0.0 & 0.34 & -0.0 to 0.0 \\
Abbreviation & $4349(3.1)$ & $4146(0.3)$ & 2.9 & $<0.001$ & 2.3 to 3.4 \\
Drug name & $4346(3.1)$ & $4146(0.3)$ & 2.9 & $<0.001$ & 2.3 to 3.4 \\
Accuracy & $4349(0.8)$ & $4146(0.6)$ & 0.2 & 0.21 & -0.1 to 0.6 \\
Drug name & $4336(0.1)$ & $4146(0.1)$ & -0.1 & 0.28 & -0.2 to 0.1 \\
Strength & $1187(0.2)$ & $911(0.0)$ & 0.2 & 0.21 & -0.1 to 0.4 \\
Route & $558(0.2)$ & $154(0.0)$ & 0.2 & 0.60 & -0.2 to 0.5 \\
Which eye & $3789(0.5)$ & $3986(0.1)$ & 0.4 & 0.001 & 0.2 to 0.7 \\
Frequency & $4349(0.2)$ & $4146(0.2)$ & 0.0 & 0.90 & -0.2 to 0.2 \\
Dispense amount & $4349(0.0)$ & $4146(0.2)$ & -0.2 & 0.004 & -0.3 to -0.1 \\
Any error & $4349(32.9)$ & $4146(3.5)$ & 29.4 & $<0.001$ & 27.9 to 30.9 \\
\hline & & & & &
\end{tabular}


$(3.1 \%-0.3 \%)$. There was a statistically significant increase in ambiguous errors with FormularyScripts $(0.6 \%-2.5 \%, \mathrm{p}<0.001)$. There was no statistically significant change in accuracy errors $(0.8 \%-0.6 \%$, $\mathrm{p}=0.21$ ).

\section{Error subtypes}

Error subtype rates were calculated and compared for handwritten and FormularyScripts based on the required fields for the different medications (table 2). Key findings from this analysis were statistically significant $(p<0.001)$ decreases in all legibility, incomplete and abbreviation error subtypes, except for legibility route, and incomplete which eye and dispensed amount. All accuracy error subtypes except dispensed amount showed a decrease or no change in error rates using FormularyScript, but only the decrease in which eye subtype reached statistical significance $(0.5 \%-0.1 \%$, $\mathrm{p}<0.001)$. There were statistically significant increases in the error rates in both ambiguous error subtypes using FormularyScripts, which eye $(0.3 \%-2.5 \%, \mathrm{p}<0.001)$ and drug name $(0.3 \%-0.6 \%, \mathrm{p}=0.03)$.

\section{Prescription elements}

The data were also analysed to determine the rate of any type of error in the required elements on each prescription (table 3). The presence of any type of error in that element was counted as an error. The denominator of possible errors was determined based on the required elements for that medication. There was a statistically significant decrease $(\mathrm{p}<0.001)$ using FormularyScripts in all prescription elements: drug name $(20.8 \%-1.1 \%)$, route $(17.0 \%-1.2 \%)$, strength $(11.8 \%-0.0 \%)$, which eye $(7.5 \%-2.6 \%)$, frequency $(5.4 \%-0.3 \%)$ and dispensed amount $(1.3 \%-0.2 \%)$.

\section{DISCUSSION}

These results indicate that medication prescribing errors are common in the outpatient ophthalmology clinic at Srinagarind Hospital and are primarily due to legibility and incomplete information. This is similar to the findings of studies done in developed countries, which found that legibility and incomplete information are the most common types of medication prescribing errors, ${ }^{12}$ and error rates of $7.6 \%-21 \% .{ }^{10}{ }^{11}$ Legibility errors, incomplete prescribing information and use of unacceptable abbreviations were decreased using FormularyScript without changing the overall rate of accuracy errors. However, there was an increase in ambiguous type of error suggesting that new ways of creating medication prescribing errors can occur.

As a non-randomised single-site interventional study, we acknowledge that this study is limited in its conclusions and is not generalisable. In addition, there are several other important limitations that need to be mentioned. Determining and classifying prescribing errors is a subjective process, especially legibility errors. We tried to address this issue through using multiple reviewers to maximise the consistency of our classification. We acknowledge that an experienced pharmacist could decipher the correct information on most of these prescriptions, but the potential for misinterpretation existed. Because of this, the anticipated impact on medication prescribing errors that could result in actually dispensing the incorrect medication is less than predicted by the study's results. Another limitation is that medications lost to follow-up (prescriptions written but not filled at the hospital pharmacy) were included in our calculations, so that $21.5 \%$ of handwritten and $5.0 \%$ of FormularyScript medications did not receive the second review by the pharmacy technician. We elected to include them because our results with and without them were unchanged. We believe that the design of the FormularyScript contributed to some ambiguous and accuracy errors as up to three medications could be written on one FormularyScript, and having only one medication per page may reduced some of the ambiguous and accuracy errors. While most physicians found the FormularyScript design acceptable and easy to use, occasionally some physicians wrote some prescriptions on the FormularyScript, even though the medications were preprinted. These were excluded from analysis, but this may have created some selection bias. The physicians in the study were aware that the prescriptions were being analysed for error rates, although the exact types and details were not disclosed. We acknowledge that this could have resulted in modification of their behaviour, or Hawthorn effect, which may have affected overall error rates in both handwritten prescriptions and FormularyScripts.

In conclusion, we believe that this study suggests that a preprinted prescription form has the potential to decrease medication prescribing errors related to legibility, incomplete prescribing information and use of unacceptable abbreviations without changing the overall rate of accuracy errors. Additional investigation is

Table 3 Error rate by prescription element in handwritten versus FormularyScript

\begin{tabular}{lccccc}
\hline Prescription element & Handwritten, N (\%) & FormularyScript, N (\%) & $\mathbf{\Delta} \%$ & $\mathbf{p ~ V a l u e}$ & $\mathbf{C l}$ \\
\hline Drug name & $4349(20.8)$ & $4146(1.1)$ & 19.7 & $<0.001$ & 18.5 to 21.0 \\
Strength & $1188(11.8)$ & $911(0.0)$ & 11.8 & $<0.001$ & 9.9 to 13.6 \\
Route & $565(17.0)$ & $161(1.2)$ & 15.7 & $<0.001$ & 12.2 to 19.3 \\
Which eye & $3789(7.5)$ & $3986(2.6)$ & 4.9 & $<0.001$ & 4.0 to 5.9 \\
Frequency & $4349(5.4)$ & $4146(0.3)$ & 5.1 & $<0.001$ & 4.4 to 5.8 \\
Dispense amount & $4349(1.3)$ & $4146(0.2)$ & 1.1 & $<0.001$ & 0.7 to 1.5 \\
\hline
\end{tabular}


indicated to determine whether or not these benefits can be realised in other settings. Even though there are several important limitations to this study, we feel that it brings attention to an important opportunity to address medication prescribing errors in low resource settings where electronic prescribing systems are not feasible. Our finding that new error types occur highlights the need to monitor any new medication prescribing system for unintended consequences. By working closely with physicians and pharmacists, design and process modifications can be made to minimise this concern, in addition to providing adequate training for users.

Author affiliations

${ }^{1}$ Department of Ophthalmology, Srinagarind Hospital, Khon Kaen University, Khon Kaen, Thailand

${ }^{2}$ Ophthalmic Consultants of Boston, Center for Eye Research and Education, Harvard Medical School, Boston, Massachusetts, USA

${ }^{3}$ Massachusetts Eye and Ear Infirmary, Harvard Medical School, Boston, Massachusetts, USA

${ }^{4}$ Department of Global Health and Social Medicine, Harvard Medical School, Boston, Massachusetts, USA

${ }^{5}$ Department of Medicine, Harvard Medical School, Boston, Massachusetts, USA

Acknowledgements We thank the WHO Patient Safety Research Small Grants for funding and technical support. All views expressed in this presentation are those of the authors and do not necessarily reflect the views of the $\mathrm{WHO}$.

Contributors TS (principle investigator): project design, oversight, implementation and manuscript preparation. MGM (co-investigator): project design, oversight and data analysis. YY (co-investigator): project oversight and implementation. AL: project design and implementation. BH: statistical analysis and manuscript preparation. KM (co-investigator): project design, oversight, data analysis and manuscript preparation.

Funding This work was supported by the WHO Patient Safety Research Small Grants (PS08169 to TS) and the Center for Eye Research and Education.

Competing interests None.
Patient consent Informed consent was obtained from all patients and staff participating in the study.

Ethics approval All procedures and protocols were approved by the Khon Kaen University Ethics Committee for Human Research and the Research Ethics Review Committee of the WHO.

Provenance and peer review Not commissioned; externally peer reviewed

Data sharing statement There are no additional data available.

\section{REFERENCES}

1. Gandhi TK, Weingart SN, Seger AC, et al. Outpatient prescribing errors and the impact of computerized prescribing. J Gen Intern Med 2005;20:837-41.

2. Mandal K, Fraser SG. The incidence of prescribing errors in an eye hospital. BMC Ophthalmol 2005;225:4

3. Kozer E, Scolnik D, MacPherson A, et al. Using a preprinted order sheet to reduce prescription errors in a pediatric emergency department: a randomized, controlled trial. Pediatrics 2005;116:1299-302.

4. Al Khaja KA, Al-Ansari TM, Sequeira RP. An evaluation of prescribing errors in primary care in Bahrain. Int $\mathrm{J}$ Clin Pharmacol Ther 2005;43:294-301.

5. Alam K, Mishra P, Prabhu M, et al. A study on rational drug prescribing and dispensing in outpatients in a tertiary care teaching hospital of Western Nepal. Kathmandu Univ Med J (KUMJ) 2006;4:436-43.

6. Biswas NR, Jindal S, Siddiquei MM, et al. Patterns of prescription and drug use in ophthalmology in a tertiary hospital in Delhi. Br J Clin Pharmacol 2001;51:267-9.

7. Hazra A, Tripathi SK, Alam MS. Prescribing and dispensing activities at the health facilities of a non-governmental organization. Natl Med $J$ India 2000;13:177-82.

8. Irshaid YM, Al Homrany M, Hamdi AA, et al. Compliance with good practice in prescription writing at outpatient clinics in Saudi Arabia. East Mediterr Health J 2005;11:922-8.

9. Oshikoya KA, Ojo OI. Medication errors in paediatric outpatient prescriptions of a teaching hospital in Nigeria. Nig Q J Hosp Med 2007; 17:74-8.

10. Meyer TA. Improving the quality of the order-writing process for inpatient orders and outpatient prescriptions. Am J Health Syst Pharm 2000;57(Suppl 4):S18-22.

11. Shaughnessy AF, Nickel RO. Prescription-writing patterns and errors in a family medicine residency program. $J$ Fam Pract 1989;29:290-5 